\title{
(1)
}

Alfonso Cavallé Cruz*

Ramón Casilda Béjar**

\section{LA SEGURIDAD DE LAS INVERSIONES EN IBEROAMÉRICA Y EL PROYECTO IBERFIDES}

América Latina constituye, desde los primeros años de la década de los noventa del pasado siglo, la región donde las principales empresas y bancos españoles iniciaron su expansión internacional. Posteriormente se le unieron una creciente cantidad de pequeñas y medianas empresas. España se sitúa como el primer inversor europeo y el segundo mundial por detrás de Estados Unidos. En un mundo cada vez más globalizado e interconectado se hace ineludible buscar soluciones prácticas que, sin merma de las garantías y seguridad, faciliten las relaciones comerciales, empresariales, interpersonales y familiares, que son especialmente intensas en el ámbito iberoamericano.

Hoy juega a favor de la creación un sistema de colaboración interinstitucional iberoamericano para la interconexión documental y de negocio utilizando las nuevas herramientas tecnológicas. La alianza de la seguridad jurídica con la tecnológica se convierte en vehículo y puente de unión facilitador de las relaciones jurídicas transnacionales y de las inversiones. Iberoamérica cuenta con sistemas comunes de seguridad jurídica preventiva, enmarcados en la Unión Internacional del Notariado (UINL), lo que puede potenciar la contratación y la circulación internacional ágil, eficiente y segura de la documentación mediante el proyecto Iberfides.

Palabras clave: multilatinas, inversiones, seguridad jurídica.

Clasificación JEL: F23, K12.

\section{Las inversiones españolas en América Latina}

\subsection{Planteamiento general}

Como es conocido, la expansión de las empresas y bancos españoles en América Latina

\footnotetext{
* Notario de Santa Cruz de Tenerife. Delegado para América del Consejo General del Notariado de España.

** Profesor del Instituto de Investigación en Estudios Latinoamericanos. Universidad de Alcalá.

Versión de diciembre de 2018.
}

ha situado a España como primer país europeo en inversión extranjera directa (IED) y en uno de los primeros del mundo en la región, solo por detrás de EEUU.

América Latina, a pesar de la crisis y el descenso del precio de las materias primas, continúa siendo una región atractiva y estratégica para las inversiones españolas, que durante el periodo 1993-2015 totalizaron $207.207 .989 \mathrm{mi}-$ llones de euros con ETVE y 169.153.940 $\triangleright$ 
millones de euros sin ETVE1, lo que refleja la importancia para nuestras empresas (Cuadro 1).

Las empresas españolas tienden a invertir en países donde los derechos de propiedad se respetan en mayor medida. Mientras que las inversiones que realizan asumiendo mayores riesgos se explican por una mejor rentabilidad. De manera que nuestras empresas y bancos invierten, preferentemente, en países industrializados o avanzados, y fuera de ellos se han especializado en América Latina, que presenta una matriz de riesgos relativamente compensada. Los destinos preferentes son Brasil (primero), México (segundo), Argentina (tercero) y Chile (cuarto). Aunque estos países concentran las preferencias inversoras, durante los últimos años se observa un repunte significativo hacia Colombia (quinto) y Perú (sexto), así como República Dominicana y Panamá por el importante desarrollo turístico y de infraestructuras, respectivamente (Cuadro 1).

Si la última década del siglo xx resultó exitosa para nuestras inversiones en América Latina, la primera década del siglo xxI se puede clasificar como vigorosa para el crecimiento económico de la región y para el avance social: 70 millones de personas abandonaron la pobreza para insertarse en una dinámica clase media.

España se ha consolidado como el principal inversor europeo, y las empresas españolas, junto con los bancos, fueron destacados protagonistas en la introducción de nuevos productos, servicios, organización, tecnología y gestión, permitiéndoles actuar como

\footnotetext{
1 Las ETVE, son sociedades establecidas en España, cuyo principal objeto es la tenencia de participaciones de sociedades situadas en el exterior. Son sociedades instrumentales cuya existencia obedece a estrategias de optimización fiscal dentro de un mismo grupo empresarial y en muchos casos sus inversiones carecen de efectos económicos directos. Las operaciones de inversión llevadas a cabo por este tipo de sociedades generalmente consisten en la transmisión dentro de un mismo grupo empresarial de participaciones en sociedades radicadas fuera de España.
}

CUADRO 1

AMÉRICA LATINA. TOTAL DE IED ESPAÑOLA, 1993-2015 (Millones de euros)

\begin{tabular}{|l|r|r|}
\hline \multicolumn{1}{|c|}{ Países } & $\begin{array}{r}\text { Total IED } \\
\text { española } \\
\text { con ETVE }\end{array}$ & $\begin{array}{r}\text { Total IED } \\
\text { española } \\
\text { sin ETVE }\end{array}$ \\
\hline Argentina & 49.269 .641 & 33.972 .041 \\
Bolivia & 463.545 & 290.820 \\
Brasil & 60.273 .254 & 54.913 .214 \\
Chile & 19.433 .894 & 18.235 .775 \\
Colombia & 8.715 .462 & 6.666 .926 \\
Costa Rica & 993.493 & 683.086 \\
Cuba & 932.566 & 932.566 \\
Ecuador & 1.439 .312 & 951.233 \\
El Salvador & 871.287 & 812.892 \\
Guatemala & 1.182 .469 & 969.028 \\
Honduras & 147.841 & 125.721 \\
México & 40.114 .592 & 34.663 .446 \\
Nicaragua & 204.992 & 197.668 \\
Panamá & 2.370 .410 & 2.258 .189 \\
Paraguay & 240.604 & 107.380 \\
Perú & 7.091 .521 & 5.846 .228 \\
República Dominicana & 1.548 .251 & 1.501 .575 \\
San Cristóbal y Nevis & 4.940 & 4.940 \\
Uruguay & $\mathbf{2 0 7 . 2 0 7 . 9 8 9}$ & $\mathbf{1 6 9 . 1 5 3 . 9 4 0}$ \\
Venezuela & 2.862 .419 \\
\hline Total IED española (1993-2015) & 3.158 .794 \\
\hline Fuente: elaboración propia según Datainvex (estadística de inver- \\
sión española en el exterior y del exterior en España. Secretaría de \\
Estado de Comercio. Ministerio de Industria, Comercio y Turismo. \\
Gobierno de España). & \\
\hline
\end{tabular}

trasmisores y palancas para la modernización sectorial y productiva de los países.

Este proceso de expansión, que les posibilitó su internacionalización, tuvo sus comienzos durante los primeros años de 1990, siendo pioneros los sectores de telecomunicaciones, banca, energía y seguros, todos ellos claves para el crecimiento y desarrollo económico de los países latinoamericanos. Posteriormente se produjo una eclosión expansiva en los distintos sectores de actividad, tales como ingeniería, construcción, infraestructuras, concesiones, textil, hostelería, consultoría y editorial, así como empresas medianas y pequeñas, y aprovecharon esta dinámica para internacionalizarse.

Toda esta actividad muestra la relevancia que ha adquirido la región para el tejido empresarial español en todas sus dimensiones, $\sin \triangleright$ 
embargo, se ha producido una sucesiva disminución de las inversiones españolas a lo largo de la presente década, en comparación con la última del siglo xx. En términos tanto absolutos como relativos, es posible que esta caída no se deba únicamente a la existencia de menores oportunidades y a la extinción de las privatizaciones, sino también a la percepción de mayores riesgos políticos y de propiedad focalizados en algunos países. El análisis de los indicadores institucionales demuestra que algunos han mostrado una mayor inestabilidad política, mayor mutabilidad del marco legal o menor cumplimiento que durante las décadas anteriores.

Sin embargo, también es cierto que muchos han mejorado su protección de los derechos de propiedad y su marco de inversiones. Por tanto, la empresa española continuará comprometiendo capital en la región, aunque lo hará identificando aquellos entornos que ofrezcan una seguridad jurídica más apropiada. Un análisis del marco legal, un estudio de la economía del país y del sector, la búsqueda de apoyo de instituciones, tanto en el país de origen como de destino, o contar con garantías contra el riesgo político son algunos de los instrumentos que los inversores pueden emplear para mitigar los riesgos según cada país, puesto que las diferencias entre ellos son manifiestas. Ya está debidamente identificado y asimilado que no hay una única América Latina, sino que cada país es diferente económica, social, institucional, cultural y políticamente. Además, la región es considerada como un crisol de culturas y razas.

\section{El surgimiento de las empresas multilatinas en América Latina}

Empresarialmente se ha producido un fenómeno importante en América Latina y el Caribe, como ha sido el surgimiento de las empresas multilatinas $^{2}$, fruto de los años de altos crecimientos, que se han visto acompañados por una fuerte expansión interregional. De hecho, durante estos años, estas empresas representan el núcleo productivo que genera mayor riqueza, con indudable repercusión tanto en el crecimiento como en el desarrollo de la región. El comportamiento de las multilatinas influye en la manera de actuar y sobre los resultados de la economía de los países, y, al mismo tiempo, moderniza sus actividades productivas; todo lo cual repercute en la inclusión de la región en los mercados internacionales, favoreciendo así a los países y el bienestar de los ciudadanos.

En consecuencia, las multilatinas impulsaron una tendencia inversora hacia España, dadas las múltiples oportunidades y ventajas que ofrecía la desaceleración de la economía debido a la crisis económica, con el consiguiente atractivo que ofrecía el mercado, cuyos precios descendieron notablemente.

Las multilatinas y los grupos de inversores que más se han destacado por sus operaciones están encabezados por los mexicanos, que se posicionan como los más activos en sectores como el cementero, bancario (aunque han deshecho las posiciones), restauración, transporte, alimentación y cárnico. Le siguen los brasileños, que, en menor medida, lo hicieron en textil, automoción y siderurgia, mientras los chilenos se encuentran muy activos en el inmobiliario. Por su parte, Colombia lo hizo en el sector bancario (aunque deshizo sus posiciones), y Venezuela, aunque se concentra en el inmobiliario, protagonizó la más importante inversión en el sector bancario, que no solo $\triangleright$

\footnotetext{
2 Para más detalle véase: Ramón Casilda Béjar; Antonio Bulnes y Carlos Loaiza Keel: Inversiones españolas en Latinoamérica. La internacionalización de las empresas españolas y el resurgimiento de la multilatinas en el siglo xxı. Thomson Reuters-La Ley. Montevideo, Uruguay.
} 
permanece, sino que la ha ampliado con nuevas adquisiciones.

Este proceso inversor en ambas direcciones resulta en sí mismo tan estimulante como beneficioso, dado que España se convierte en la plataforma o hub de inversiones latinoamericanas para Europa, principalmente. Por tal motivo, es necesario apoyar y promocionar iniciativas conducentes a favorecer y dar seguridad jurídica a las inversiones. Por ejemplo, solo en México se encuentran registradas casi seis mil empresas españolas, que son en su amplia mayoría pequeñas y medianas (pymes).

En este sentido, el Consejo General del Notariado, consciente de la trascendencia que representa este esfuerzo inversor, así como de las consecuencias positivas que su profundización tiene para el fortalecimiento de la Comunidad Iberoamericana, impulsa, junto con la Unión Internacional del Notariado (UINL), el fortalecimiento del principio de confianza mutua entre los Estados que la conforman, así como la aproximación de sus legislaciones en el ámbito de la fe pública y de la circulación de los documentos públicos, lo cual se trata en la segunda parte de este trabajo mediante el proyecto Iberfides.

Este proyecto tiene como apoyo el aprovechamiento de las nuevas tecnologías, que constituyen una apuesta estratégica del notariado iberoamericano, presentándose estas como perfectas aliadas para superar la limitación espacio-tiempo que, objetivamente, dificultan las relaciones entre los países, y se consigue incrementar el nivel de seguridad jurídica, viéndose acompañada de una drástica reducción de costes transaccionales.

Así, la garantías que aporta la intervención de los notarios iberoamericanos, a instancia de empresas o particulares de distintas nacionalidades, interesados en la perfección y seguridad de un acto o contrato, tanto en la fase previa a la contratación de bienes y servicios como en el momento del otorgamiento del consentimiento incorporado al documento público autorizado, no solo añaden garantías objetivas de legalidad, sino también aquellos efectos que de modo común le atribuyen los ordenamientos jurídicos iberoamericanos a tal documento público: fehaciencia y ejecutividad (Casilda y Prats, 2014).

Esta iniciativa del notariado iberoamericano debe obtener el respaldo político, económico y social. Para lo cual, el Consejo General del Notariado, con el apoyo de la Secretaría General Iberoamericana (SEGIB) y la Secretaría de Cooperación Internacional y para Iberoamérica y el Caribe, organiza periódicamente actividades de difusión y reflexión como son las jornadas sobre «Seguridad Jurídica Iberoamericana», donde cada año se trata un tema o temas específicos jurídicos, económicos y sociales.

\section{El proyecto Iberfides}

\subsection{Antecedentes}

Los vínculos entre España y América son una realidad centenaria que afecta a todos los ámbitos: el idioma, las costumbres, la cultura, el derecho, el comercio y en la vida de las personas y los pueblos. Estas vinculaciones son muy acentuadas en derecho privado y comercial y tienen su reflejo en instituciones, como la notarial, presente a través de los escribanos desde el mismo momento del descubrimiento del Nuevo Mundo. Hoy puede hablarse en Hispanoamérica de una tradición jurídica común, conservada y desarrollada.

De los distintos derechos hispanos fue el derecho castellano el que se aplicó al Nuevo Mundo, por ser Isabel de Castilla quien apoyó la $\triangleright$ 
aventura de Colón. A la rápida extensión contribuyeron los escribanos, que desempeñaron un papel fundamental en la cohesión jurídica y social de los nuevos pueblos y ciudades. La mutación del marco jurídico en Hispanoamérica superó en celeridad e intensidad a la propagación del derecho romano, y su influencia, tras la independencia, subsiste adaptada a las realidades de las distintas naciones. Hoy hablamos de comunidad hispanoamericana de derecho privado porque compartimos raíces, influencias y principios comunes. $Y$ esta influencia recíproca se mantiene en la actualidad con renacida intensidad.

Hay que tener muy en cuenta que la presencia de los escribanos en América (hoy llamados en muchos países notarios) es anterior a la creación en 1511 de la primera Audiencia en Santo Domingo. Las primeras líneas de la historia de Hispanoamérica vinieron dadas de la mano de Rodrigo Escobedo, escribano que acompañó a Cristóbal Colón en su primer viaje, a quien le correspondió el 12 de octubre de 1492 dejar constancia escrita y dar fe de la toma de posesión en nombre de los Reyes Católicos de las tierras recién descubiertas.

La presencia notarial en esos primeros años no fue excepcional, sino la regla general. Al Nuevo Mundo, junto con la cruz y la espada, también viajó la pluma, que en manos de los escribanos representó la paz social, el orden y el derecho. Desde el principio, en todos los actos con trascendencia jurídica de los conquistadores estuvo presente un escribano que dejó recuerdo y constancia de la toma de posesión, fundación de ciudades y, en general, de todos los hechos con relevancia jurídica. Así, por ejemplo, el escribano Diego de Godoy levantó acta de la constitución del primer ayuntamiento del territorio continental el 10 de junio de 1519, la Villa Rica de la Vera Cruz; de la fundación de la Ciudad de México, el 8 de marzo de 1524, dio fe el escribano Francisco de Orduña. También Francisco Pizarro se hizo acompañar del escribano Pedro Sánchez de la Hoz. Hoy se conserva en el Archivo General del Perú el Protocolo ambulante de los conquistadores, también conocido como Libro becerro, que abarca un periodo comprendido entre 1533 y 1542, en el que se contienen las escrituras autorizadas por los escribanos que acompañaron a los conquistadores en su periplo por Cajamarca, Jauja, Piura, Cuzco, Lima, Chile y Argentina. Ciertamente, para conocer la historia de América y España hay que acudir a la rica fuente constituida por los protocolos notariales. En ellos quedaron plasmados no solo los grandes hechos, también la vida de las personas y de los pueblos, sus realidades cotidianas, familiares, patrimoniales, sus sentimientos y creencias, y dotaron de certeza y seguridad las relaciones jurídicas entre los particulares.

Además de las realidades sociales y jurídicas en las tierras recién descubiertas, los protocolos notariales centenarios dejaron remembranza y prueba fehaciente del comercio y de las intensas y frecuentes vinculaciones socioeconómicas entre los habitantes de ambos lados del Atlántico. Escrutando los protocolos del siglo xVI, se evidencia que, a los pocos años del descubrimiento, las relaciones jurídicas familiares y comerciales transatlánticas eran fluidas y habituales. Hoy, quinientos años después, la sociedad demanda reeditar en los países iberoamericanos una interconexión documental adaptada al siglo xxI, que facilite y agilice las relaciones jurídicas, familiares, civiles y comerciales, dotándolas de seguridad, certeza y eficiencia.

\subsection{Situación actual}

En un mundo cada vez más globalizado e interconectado se hace ineludible buscar $\triangleright$ 
soluciones prácticas que, sin merma de las garantías y seguridad, faciliten las relaciones comerciales, empresariales, interpersonales y familiares, que son especialmente intensas en el ámbito iberoamericano.

Hoy juega a favor de la creación un sistema de colaboración interinstitucional iberoamericano para la interconexión documental y negocial utilizando las nuevas herramientas tecnológicas $y$, también, los siguientes elementos aglutinadores:

- La comunidad idiomática. Según el Instituto Cervantes, en el año 2017, son más de 600 millones de personas las que hablan castellano, de las cuales la mayoría están en el continente americano. El segundo idioma en la región es el portugués, que, al igual que el castellano, es una lengua del grupo iberorromance, con grandes similitudes que facilitan la comunicación.

- Un segundo elemento aglutinador y facilitador es la existencia de una tradición jurídica común, que hace que la terminología técnico-jurídica sea, en gran medida, coincidente, lo que facilita la contratación y la interpretación.

- Y el tercer elemento, y no por ello el menos importante, cuenta con sistemas documentales análogos y notariados que comparten principios comunes, actualmente integrados en la Unión Internacional del Notariado (UINL).

Aprovechando estas tres ventajas surge el proyecto Iberfides, que trata de dar respuesta a esa necesidad de conectar negociadora y documentalmente Iberoamérica, facilitando las relaciones de negocio, empresariales y familiares. Iberfides desplegará su utilidad entre aquellos países de Iberoamérica que cuenten con notariados bien regulados y adaptados a los principios de la UINL, es decir, con notariados del sistema latino-germánico, respeto al principio de equivalencia de formas, con documentación dotada de similares efectos, calidad y que cuenten con la garantía de sus Estados a fin de que gocen de la máxima seguridad y eficacia.

\subsection{La circulación segura de documentos notariales electrónicos}

En el espacio iberoamericano la circulación de personas y empresas es cada vez más intensa, lo que urge a facilitar, al máximo, la circulación de documentos auténticos, con plena seguridad y garantías, al tiempo que se ahorra tiempo, se evitan desplazamientos y disminuyen costes.

La experiencia mantenida en España en las últimas décadas ha sido fructífera y pueden servir de ejemplo de buena práctica.

El notariado español es el colectivo pionero y más activo en el proceso de implantación de la administración electrónica. Desde hace años, cualquier copia autorizada electrónica de una escritura puede remitirse de forma inmediata, por ejemplo, de una notaría de Galicia a otra de las Islas Canarias, con las máximas garantías y seguridad. Esto se realiza de forma confidencial a través del ciberespacio por medio de los servicios centrales de la Agencia Notarial de Certificación (ANCERT), usando las firmas electrónicas avanzadas y reconocidas con cifrado de datos, tanto por el notario que la envía como por el notario receptor. La copia autorizada electrónica goza de idéntico valor legitimador, autenticidad y efectos que la tradicional copia autorizada en papel (art. 17 bis de la Ley del Notariado). Estos envíos telemáticos se $\triangle$ 
efectúan cotidianamente a otras notarías y a otros organismos públicos. Las comunicaciones se llevan a cabo a través de una red de telecomunicaciones exclusiva, la Red Notarial de Servicios Integrados (RENO). Gracias a su existencia se ha agilizado el tráfico jurídico sin merma de seguridad y con un claro beneficio para los ciudadanos en ahorro de tiempo, desplazamientos y costes.

Desde su entrada en funcionamiento, hace más de una década, han sido millones las copias electrónicas autorizadas remitidas entre notarios, con total seguridad, sin que se haya producido el más mínimo incidente. La seguridad de los procesos telemáticos notariales es de las más altas a nivel mundial a fin de generar la máxima confianza en la privacidad, solvencia tecnológica y seguridad de los sistemas. La utilización de la firma electrónica por el notariado español se remonta a la Ley 24/2001 de 27 de diciembre, que, en el art. 17 bis de la Ley del Notariado, estableció las bases del documento público notarial electrónico.

La plataforma tecnológica del notariado español es la Agencia Notarial de Certificación (ANCERT), cuya primera función fue gestionar la autenticación, generación de firma electrónica avanzada y reconocida de los notarios y cifrado de datos. La firma electrónica notarial permite al notario acceder a la intranet notarial (SIC) o al Sistema Integrado de Gestión del Notariado (SIGNO) y a un, cada vez más relevante, abanico de servicios a la ciudadanía y de colaboración con las Administraciones Públicas.

Este sistema de colaboración notarial descrito, con las lógicas adaptaciones, puede trasladarse e implementarse entre países de Iberoamérica.

Son muchos los ejemplos de los documentos que cada día se remiten entre continentes y entre países de Iberoamérica. Por ejemplo, en el campo de los negocios jurídicos, tanto civiles como mercantiles: constituciones de sociedades, poderes, ratificaciones y un sinnúmero de contratos civiles y mercantiles. En el ámbito de las relaciones familiares: las autorizaciones para viajar, documentos para reagrupación familiar, autorizaciones en materia de ejercicio de patria potestad, títulos académicos, documentos para el cobro de pensiones, entre otros muchos. Hoy su utilidad es incuestionable, pues contamos con la experiencia contrastada de circulación segura de documentos electrónicos notariales en España. Apoyándonos en esta experiencia, es imprescindible articular convenios que permitan la colaboración entre los notariados de los distintos países para lograr también en el ámbito iberoamericano un sistema seguro de circulación de documentos notariales.

\subsection{Colaboración notarial en operaciones transnacionales en Iberoamérica: Iberfides}

Un paso más allá de la mera circulación documental es la colaboración institucional con el fin de facilitar la celebración de negocios transnacionales válidos y eficaces. La globalización también ha llevado como consecuencia la internacionalización de la contratación, a la cual ha de darse respuesta. Centrándonos en el ámbito iberoamericano y en la común existencia de notariados del tipo latino-germánico, más conocido por notariado latino, nos ofrece en la región una puerta abierta a que los otorgantes, sin salir de su país de residencia, puedan formalizar con absoluta garantía un acto o contrato que producirá sus efectos en otro país de Iberoamérica.

Las similitudes entre notariados, idioma y conceptos jurídicos, como ya indicamos, $D$ 
facilitan sobremanera que un inversor, o cualquier persona, pueda acudir al notario de confianza de su país de residencia para que, en colaboración con el notario del país de destino del negocio y del documento, formalice el negocio $u$ operaciones transfronterizas que se proponga realizar en otro país con absoluta garantía. La colaboración entre notarios es lo que permite optimizar al máximo el asesoramiento y control de legalidad, tanto material como formal. Estas ideas se pretenden desarrollar con el proyecto Iberfides de colaboración entre notarios del espacio iberoamericano.

Este proyecto se inspira en su hermano mayor, el proyecto Eufides, que se está desarrollando entre los países miembros de la Unión Europea que cuentan con notariado latino, un total de 22 de los 28 que la integran. Frente a los sistemas anglosajones, el notariado latino es hoy el más extendido en el panorama internacional. Actualmente, se encuentra implantado en alrededor de 120 países, que representan $2 / 3$ de la población mundial y más del $60 \%$ del producto interior bruto mundial. La mayor parte de ellos están integrados en la UINL. Actualmente forman parte de la UINL 88 países, 15 de ellos miembros de los 19 que integran el G20.

Iberfides dará respuesta no solo a la contratación mercantil, también a la inmobiliaria y, en general, a toda clase de actos y negocios jurídicos, tanto civiles como mercantiles, como lo serían, por ejemplo, la constitución de sociedades, la transmisión de acciones o participaciones, la adquisición y transmisión de inmuebles, las escrituras de partición de herencia o liquidación de sociedades conyugales, entre otros muchos actos y contratos.

El sistema pivota en la colaboración entre un notario de la nación de residencia de los otorgantes y un notario de la nación donde el documento va a desplegar sus principales efectos. Esta colaboración abarca la fase precontractual de preparación o redacción, la fase de otorgamiento y la fase postcontractual, etapa que incluye trámites como la presentación en registros públicos y pagos de impuestos.

En los países donde se implante el proyecto Iberfides, los notarios, además de ser de forma inescindible oficiales públicos y profesionales del derecho, han de reunir las características que exige la UINL para ser miembro.

Conforme a las exigencias de la UINL, los notarios han de ejercer una función pública, en el marco de una profesión independiente y reglada. Como oficial público, actúa por delegación de la autoridad del Estado, de modo que los documentos que redacta, de los cuales es el autor, y cuya conservación asegura, son documentos públicos o auténticos, de modo que tengan fuerza probatoria y ejecutiva.

Además, desde el punto de vista del notario, deben cumplirse los siguientes requisitos: que controlen la legalidad, es decir, que elaboren documentos conforme a la ley, interpretando la voluntad de las partes, adecuándola a las exigencias legales; que den fe de conocimiento o de identidad de las personas; que se aseguren, bajo su responsabilidad, de la capacidad y legitimación de los otorgantes, en relación al acto o negocio jurídico concreto que se pretenda realizar; que garanticen que no existen vicios del consentimiento, comprobando que la voluntad informada ha sido dada con libertad en su presencia.

Desde el punto de vista del documento, este ha de cumplir los requisitos y debe tener el mismo valor y efecto en el país de origen que en el país de destino. El documento notarial extranjero debe respetar, por tanto, además de las formas adecuadas al lugar de celebración locus regitactum, los requisitos exigidos por $\triangleright$ 
la ley aplicable al fondo. Veamos la mecánica con un ejemplo:

\section{Elección del notario de confianza}

Unos inversores residentes en un país « $A$ » quieren realizar una inversión en otro país «B», consistente en la adquisición de un inmueble.

Los inversores, sin necesidad de desplazarse fuera de su país, acuden al notario de su confianza « 1 » en su país de residencia « $A$ » para que formalice el contrato.

El notario «1», en un primer momento, dialogará con los requirentes a fin de recabar datos e indagar cuál es su voluntad y qué fines empíricos persiguen, y determinar qué negocio jurídico es el que se ajusta a lo requerido.

Solicitud de colaboración al notario del país destinatario de la inversión

Seguidamente, el notario «1» contacta por escrito con un notario «2» del país «B» y le solicita su colaboración. La colaboración tiene por fin que le indique si el negocio es viable y qué requisitos deberán cumplirse, conforme a las leyes del país «B», para asegurar la validez y eficacia del contrato.

La solicitud de colaboración se efectuará por medio de un formulario, con un contenido que podrá ser ampliado o adaptado en función de las peculiaridades del caso concreto.

\section{Aceptación de la colaboración}

Una vez recibida la comunicación de solicitud de colaboración, el notario receptor «2» deberá aceptarla o rechazarla motivadamente.

El notario «2», si aprecia que el contrato es viable, acepta la colaboración, lo que comunica por escrito al notario «1». La aceptación implica un primer control de legalidad, en vista de los datos aportados y las normas aplicables al fondo de la cuestión. La aceptación supone el compromiso del notario «2» de facilitar al notario « 1 » información, realizar un control de legalidad y facilitar el cumplimiento de los requisitos exigidos por la legislación del país «B».

Contenido de la colaboración en la fase previa al otorgamiento

Una vez aceptada, el notario «2» informará al notario «1» de cuál es la documentación a exigir para llevar adelante la operación, requisitos civiles y administrativos que han de cumplirse, los impuestos, gastos notariales, registrales, de gestión y cualesquiera otros que graven la operación. La información versará sobre la legislación local vigente (en materia civil, tributaria, fiscal, administrativa, registral y cualquier otra legislación aplicable) y requisitos que afecten al contenido con el que se redactará el documento.

El notario «2» solicitará, en su caso, información cuando el notario «1» no pueda obtenerla directamente de registros públicos inmobiliarios y catastros, sobre la situación jurídica y fáctica del inmueble, de registros de personas jurídicas, de vigencia de poderes, por ejemplo. También podrá, en su caso, realizar otros trámites dirigidos a la obtención de números de identificación fiscal, copias autorizadas de escrituras, certificados de eficiencia energética, licencias o autorizaciones administrativas, certificados de comunidades de propietarios sobre el estado de deudas, certificados del estado de deudas con ayuntamientos o cualesquiera otros que sean necesarios o convenientes. Esta información previa garantizará:

- El efectivo asesoramiento a los otorgantes, previo y simultáneo a la prestación $\triangleright$ 
del consentimiento, logrando que sea un consentimiento formado e informado.

- La realización de un efectivo control de legalidad en el momento oportuno, el del otorgamiento. Con lo que se evita que se otorguen contratos que no cumplan con los requisitos legales y se garantiza el total cumplimiento del ordenamiento jurídico aplicable.

- Se logra una redacción del documento a un tiempo ajustada a la voluntad de las partes y a la ley.

\section{Forma del acuerdo de colaboración}

El acuerdo de colaboración entre el notario «1»y «2» debe constar en un escrito donde se detallan las actuaciones y obligaciones de cada uno de los notarios, a modo de protocolo de actuación, desde el inicio hasta la conclusión de todos los trámites, para la plena efectividad del negocio.

Sobre esta información, y una vez cumplidos los requisitos, el notario « 1 » redacta y autoriza el documento, y remitirá al notario «2» copia autorizada del contrato para que la protocolice y culmine los trámites necesarios, especialmente los fiscales y de inscripción en registros públicos.

Para asegurar la autoría e integridad del contenido de los mensajes que se intercambiarán entre los notarios, además de la solicitud de colaboración y la aceptación, también deberán realizarse por escrito las demás comunicaciones a través de mecanismos electrónicos fiables, que deberán ser fijados por las corporaciones notariales de cada país.

\section{Redacción del documento}

También el notario «2» facilitará al notario «1» información que afecta a la redacción del documento, indicando los requisitos y contenidos necesarios o convenientes que ha de contener, facilitando incluso esquemas, borradores o minutas. La escritura, que redactará el notario «1» según la información recibida, teniendo en cuenta la realidad de cada país y de las peculiares circunstancias del caso concreto, podrá proponer que el documento definitivo contenga autorizaciones o poderes especiales, a favor del apoderado, de gestores u otros profesionales, o de personas de confianza de los otorgantes o del notario «2», para comparecer, intervenir en procedimientos o realizar actos, a efectos administrativos que sean necesarios o convenientes.

\section{Otorgamiento y autorización del documento}

Una vez redactado el documento, cumplidos los requisitos y obtenidas todas las certificaciones, licencias o autorizaciones correspondientes, y tras asesorar a las partes según las reglas generales y a la información recibida, el notario «1», hechas las comprobaciones pertinentes, juicio de identidad, capacidad, control de legalidad, justificación de los medios de pago y cualquier otro requisito, que asegure la legalidad del otorgamiento y su adecuación a la voluntad de los otorgantes, procederá al otorgamiento y a la autorización del documento.

\section{Remisión de copia autorizada}

Una vez autorizado el documento, el notario «1» expedirá copia autorizada, que, ya apostillada o legalizada, la remitirá al notario «2».

En este punto será conveniente que en un futuro próximo se establezcan regulaciones que faciliten circulación de copias autorizadas notariales electrónicas, en la forma que se indicó anteriormente, lo que agilizará enormemente el tráfico documental. 
Protocolización e inclusión en los índices

Una vez que el notario «2» reciba la copia autorizada, la protocolizará, con el resto de la documentación complementaria, como el convenio de colaboración, los trámites realizados y la documentación solicitada y remitida al notario extranjero. La protocolización además facilitará que se puedan incorporar los datos esenciales del negocio jurídico a los índices correspondientes, a fin de cumplir con los deberes de colaboración con las autoridades administrativas, en especial con Hacienda, así como con las autoridades judiciales y las unidades de inteligencia financiera a los efectos de la lucha contra el lavado de activos.

Si afecta a bienes inmuebles, se comunicará al catastro la operación realizada, a fin de que se haga constar la alteración catastral; y si el acto es inscribible, se procederá a presentar la copia del documento para su inscripción.

\section{Tramitación posterior}

El notario «1», conforme a las indicaciones del notario «2», deberá retener, de los sujetos pasivos y obligados al pago, las cantidades necesarias para hacer frente a los costes fiscales, tributarios, arancelarios y registrales que tendrán que ser abonados en la jurisdicción local o nacional del país donde va a producir efectos. Estas cantidades, como provisión de fondos, serán transferidas a la cuenta que el notario «2» indique a los efectos de hacer frente a los gastos e impuestos que se devenguen.

\section{Finalización}

Una vez culminados los trámites posteriores, como son los relativos a pagos de impuestos e inscripción en registros públicos, se remitirá al notario «1» copia autorizada de la protocolización, en la que incluirán los documentos donde conste la colaboración, con las constancias de los pagos de impuestos, inscripciones y trámites, concluyendo así la colaboración notarial.

\section{Conclusiones}

Transcurridas casi tres décadas desde que España iniciara el proceso inversor en la región, contemplando una visión amplia e intensa, quizás sea el momento de emprender una reformulación ambiciosa de las relaciones económicas y comerciales iberoamericanas, dotándolas de una nueva dimensión. Dicha reformulación debe aprovechar la combinación de las nuevas oportunidades que ofrece América Latina, como el proyecto Iberfides.

Iberfides trata de dar respuesta a la necesidad de conectar negociadora y documentalmente toda Iberoamérica, facilitando las relaciones de negocio, empresariales y familiares. Iberfides desplegará su utilidad entre aquellos países de América Latina que cuenten con notariados bien regulados y adaptados a los principios de la Unión Internacional del Notariado, es decir, con notariados del sistema latino-germánico, por respeto al principio de equivalencia de formas, con documentación dotada de similares efectos, calidad y que cuenten con la garantía de sus Estados a fin de que gocen de la máxima seguridad y eficacia.

Iberfides dará respuesta no solo a la contratación mercantil, sino también a la inmobiliaria $y$, en general, a toda clase de actos y negocios jurídicos, tanto civiles como mercantiles, como lo serían, por ejemplo, la constitución de $\triangleright$ 
sociedades, la transmisión de acciones o participaciones, la adquisición y transmisión de inmuebles, las escrituras de partición de herencia o liquidación de sociedades conyugales, entre otros muchos actos y contratos. Las personas, las familias y las empresas disfrutarían de estas ventajas evitando traslados intercontinentales, pérdidas de tiempo, sorpresas no gratas y un enorme ahorro de costes.

\section{Bibliografía}

[1] Casilda Béjar, R. y Prats Albentosa, L. (2014). Inversiones y seguridad jurídica en Iberoamérica. El País. Madrid, 21 de octubre de 2014.

[2] Casilda Béjar, R.; Bulnes, A. y Loaiza Keel, C. (2018). Inversiones españolas en Latinoamérica. La internacionalización de las empresas españolas y el resurgimiento de las multilatinas en el siglo xxı. Montevideo, Uruguay: Thomson Reuters-La Ley. 